\title{
Automatic generation control of two area interconnected power system using particle swarm optimization
}

\author{
Jeevithavenkatachalam ${ }^{1}$, Rajalaxmi. $S^{2}$ \\ ${ }^{I} P G$ Student/Dept. ofEEE ,PaavaiEngineering college,Nammakal, \\ ${ }^{2}$ Associate Professor/Dept. of EEE, Paavai Engineering college,Nammakal,
}

\begin{abstract}
The main objective of Automatic Generation Control (AGC) is to maintain the balance between the total system generations against system load losses so that the desired frequency and power interchange with neighboring systems is maintained. If any mismatch occurs between generation and demand causes the deviation in the system frequency from its nominal value. Thus high frequency deviation may lead to system collapse. In order to maintain the stability, a very fast and accurate controller is needed to maintain the nominal system frequency. This paper presents the particle swarm optimization (PSO) technique to optimize the integral controller gains for the automatic generation control (AGC) of the interconnected two area power system. Each control area includes the dynamics of thermal systems. The Integral Square of the error and the integral of time-multiplied absolute value of the error performances indices are considered. The results reported in this paper demonstrate the effectiveness of the particle swarm optimizer in the tuning of the AGC parameters. The enhancement in the dynamic response of the power system is verified. The result of the proposed work is compared with artificial intelligent controller.

Keywords:Automatic generation control (AGC), Area control error(ACE), Integral squared error(ISE) Integral absolute time error(ITAE), Particle Swarm Optimization (PSO).
\end{abstract}

\section{Nomenclature}

$\Delta \mathrm{F}=$ Frequency deviation.

$\mathrm{i}=$ Subscript referring to area $(\mathrm{i}=1,2 \ldots)$.

$\Delta \mathrm{P}_{\text {tie }(\mathrm{i}, \mathrm{j})}=$ Change in tie line power.

$\Delta \mathrm{Pdi}=$ Load change of ${ }^{\text {th }}$ area.

$\mathrm{Di}=\Delta_{\mathrm{PDi}} / \Delta_{\mathrm{Fi}}$

$\mathrm{R}_{\mathrm{i}}=$ Governor Speed regulation parameter for $\mathrm{i}^{\text {th }}$ area.

$\mathrm{T}_{\mathrm{hi}}=$ Speed governor time constant for $\mathrm{i}^{\mathrm{th}}$ area. $\mathrm{T}_{\mathrm{ti}}=$ Speed turbine time constant for $\mathrm{i}^{\text {th }}$ area.

$\mathrm{T}_{\mathrm{Pi}}=$ Power system time constant fori ${ }^{\text {th }}$ area.

\section{Introduction}

Automatic generation control is one of the most important issues in power system design. The main purpose of AGC is used for fast minimization of area frequency deviation and mutual tie-line power flow deviation of areas for stable operation of the system. The overall performance of AGC in any power system is depends on the proper design of speed regulation parameters and gains of the controller.The AGC action is guided by the Area Control Error (ACE) which is a function of system frequency and tie line flows. Here the ACE represents a mismatch between area load and generation by taking account into any interchange agreement with the neighboring areas [1], [2]. In the load frequency control problem, frequency and tie-line power should be kept as near scheduled value as possible, which is difficult to achieve due to fluctuating nature of the load.The frequency and the interchanged power are kept at their desired values by means of feedback of the area control error (ACE) integral, containing the frequency deviation and the error of the tie line power, and controlling the prime movers of the generators.

The controllers so designed regulate the area control error to zero. For each area, a bias constant determines the relative importance attached to the frequency error feedback with respect to the tie-line power error feedback.

(a) The steady-state frequency error following astepload change should vanish. The transient frequency andtime errors should be small

(b) The static change in the tie power following a step load in any area should be zero, provided each area can accommodate its own load change.

(c) Any area in need of power during emergency should be assisted from other areas. 
Many investigations in the area of AGC problem in interconnected power systems have been reported in the past six decades (Ibraheem and Kothari, 2005; Shayeghi et al., 2009). A number of control schemes have been employed in the design of AGC controllers in order to achieve better dynamic performance. Among the various types of AGC controllers, the most widely used are classical proportional-integral and proportionalintegralderivative (PID) controller.

After that Nanda et al. (2006) dealt with AGC of a multi area hydro-thermal system including generation rate constraints. Optimization of integral controller and electric governor parameters had been carried out using ISE criterion. Investigations had been made for the selection of suitable value for governor speed regulation parameter and to explore the effect of tie line strength on the dynamic response. However, the recent advancement in optimal control theory and availability of fast digital computers coupled with enormous capability of handling large amount of data with different type of interconnections motivated the power system engineers to devise recent AGC strategies. There have been a vast variety of research articles (Ibraheem and Kothari, 2005) relating to AGC controller designs which had made classical controllers structure as the basis for the development of more advanced and even intelligent technique (IT) based controllers for AGC applications in power systems.

Akanksha, et.al [5] dealt with Automatic Generation Control (AGC) of a five area interconnected power system with reheat turbines. Here ANN controller controls the inputs of each area in the power system together. To improve the controller performance, the proposed controller makes use of the load perturbation as input control signal, which is not used in the conventional integral controller. Back Propagation algorithm is worked out and the controller is shown to be viably applicable to practical power systems. It is concluded that ANN controller performance is better than that of integral controller in terms of peak overshoot, settling time.

In this work, we seek the optimum adjustment of the classical AGC parameters using particle swarm optimization and two objective functions which are functions of error and time. These are the integral of the square of the error criterion (ISE), and the integral of time-multiplied absolute value of the error criterion (ITAE).The latter penalizes long-duration transients and is much more selective than the ISE.
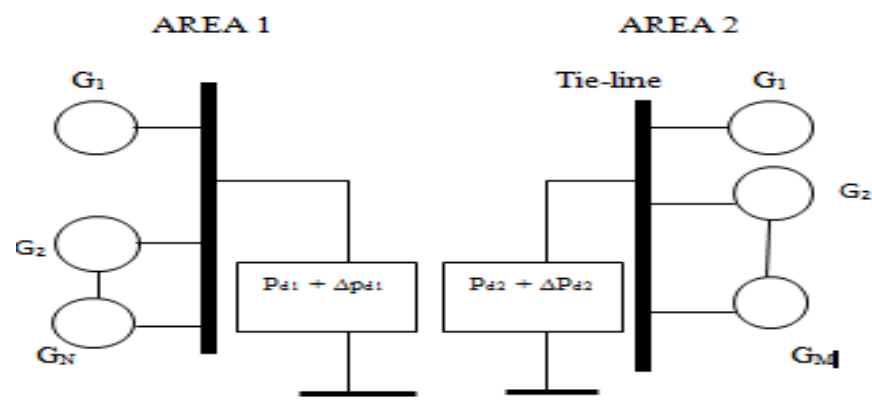

Fig.1. Configuration of an uncontrolled two-area power system.

\section{Plant Model Description}

The two-area interconnected power system is taken as a test system in this study, which consists of reheat turbine type thermal unit in each area. The model of the system under consideration is as shown in Fig. 2 , where symbols have their usual meanings. The conventional AGC scheme has two control loops: The primary control loop, which controls the frequency by self-regulating feature of the governor, however, frequency error is not fully eliminated; and the supplementary control loop, which has a controller that can eliminate the frequency error with the help of conventional integral control action. The main objective of the supplementary control is to restore balance between each control area load and generation after a load perturbation so that the system frequency and the tie-line power flows are maintained at their scheduled values. So the control task is to minimize the system frequency deviation $\Delta \mathrm{fl}$ in area $1, \Delta \mathrm{f} 2$ in area 2 and the deviation in the tie-line power flow $\Delta \mathrm{P}_{\text {tie }}$ between the two areas under the load disturbances $\Delta \mathrm{Pd} 1$ and $\Delta \mathrm{Pd} 2$ in the two areas. This is achieved conventionally with the help of integral control action. The supplementary controller of the $\mathrm{i}^{\text {th }}$ area with integral gain $\mathrm{K}_{\mathrm{i}}$ is therefore, made to act on $\mathrm{ACE}_{\mathrm{i}}$, given by (1), which is an input signal to the controller. 


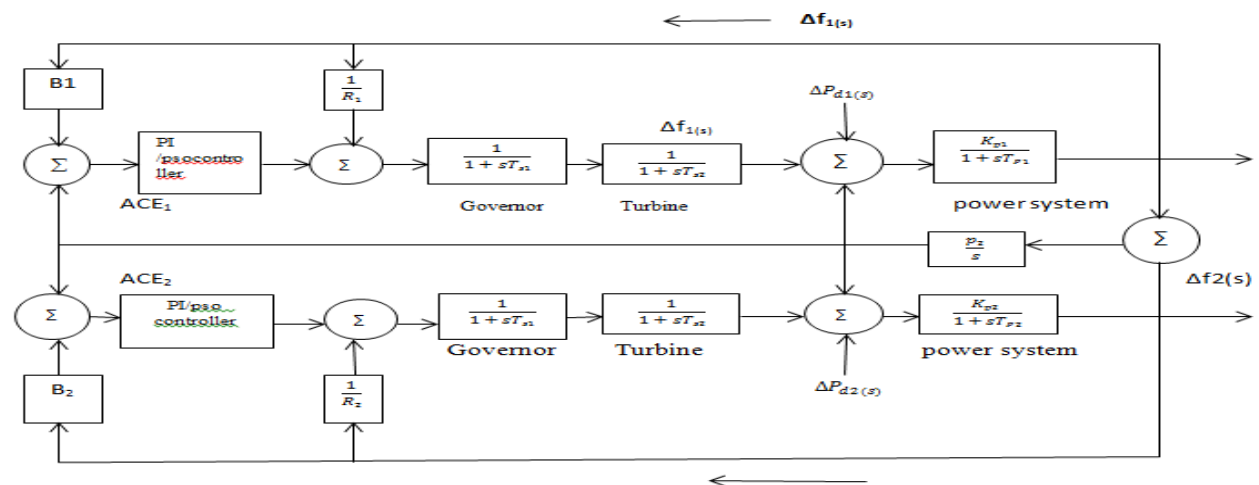

Fig.2. Transfer function model of two-area reheat power system

\section{Conventional AGC system}

Automatic control system of close loop system means minimizing the area control error (ACE) to maintain system frequency and tie-line deviation are set at nominal value.Block diagram of two area system is shown in fig.1.

The ACE of each area is linear combination of biased frequency and tie-line error.

$\mathrm{ACE}_{\mathrm{i}}=\sum_{\mathrm{j}=1}^{\mathrm{n}} \Delta \mathrm{p}_{\mathrm{tie}, \mathrm{ij}}+\beta_{\mathrm{i}} \Delta \mathrm{f}_{\mathrm{i}}(1)$

Where,

$A C E_{i}$ is the area control error of the $i^{t h}$ area

$\Delta f_{i}=$ frequency error of $i^{\text {th }}$ area

$\Delta p_{t i e, i j}=$ tie- line power flow error between $i^{t h}$ and $j^{\text {th }}$ area

$B_{i}=$ frequency bias coefficient of $i^{t h}$ area.

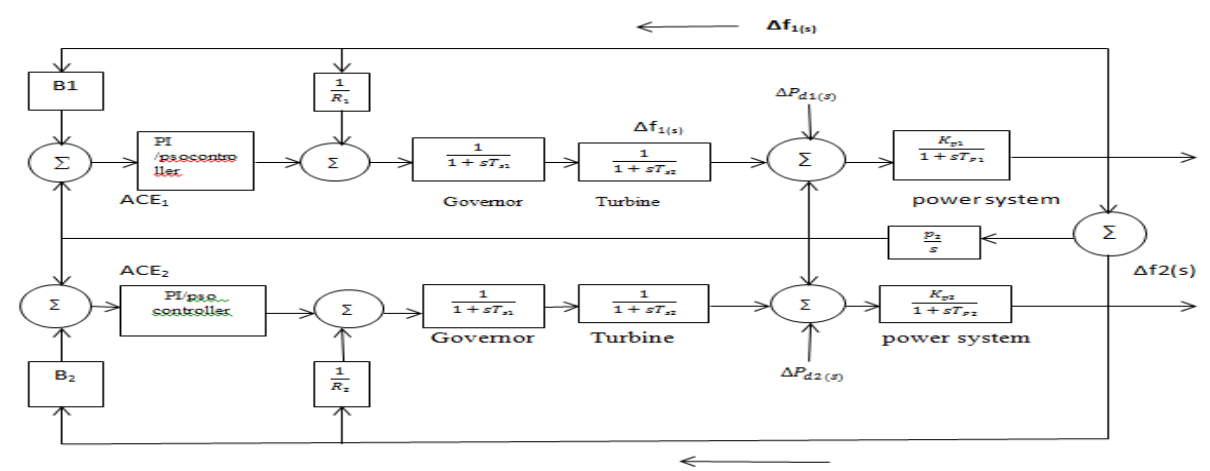

Fig.3.Linear model of two area system.

\section{Optimization Of The Integral Gain Ki, And Frequency Bias Factors Bi}

In this study, we have considered $\mathrm{B} 1=\mathrm{B} 2=\mathrm{B}$ and $\mathrm{Ki} 1=\mathrm{Ki} 2=\mathrm{Ki}$. We need to optimize $\mathrm{B}$ and $\mathrm{Ki}$ values, in order to obtain good dynamic response of the AGC system. In this study B and Ki values are optimized using the integral squared error (ISE),( integral time area error)ITAE technique by minimizing the quadratic performance index (PI) given by (4) for 0.01 p.u. step load change in area-1. Where,w1 and w2 are the weight factors both of which are chosen as 0.25 for the system considered. The optimal value of $\mathrm{Ki}=0.4167$ and $\mathrm{B}=0.8$ which occurs at a minimum value of $P I=0.9821$.

ISE:

Integral square error

ISE $=\int_{0}^{T} A C E^{2}{ }_{1}+A C E^{2}{ }_{2} \mathrm{dt}$

ITAE:

Integral Time absolute error

ITAE $=\int_{0}^{T} t\left(\left|A C E_{1}\right|+\left|A C E_{2}\right|\right) \operatorname{dt}(3)$ 


\section{Overview On PSO Technique}

PSO is a population based optimization technique based on intelligent scheme developed by Kennedy and Eberhart (1995) (Kennedy et al., 2007). PSO has emerged as one of the most assuring optimizing schemes for effectively dealing near to global optimization tests. The inspiration of the mechanism is established by the social and cooperative nature represented by flying birds. The algorithm simulates a simplified social milieu in capable solutions of a swarm which means that a single particle bases its search on its own experience and information given by its neighbors in the specified region. Particles are flown in the solution region with their randomized assigned velocity. Among these particles, each particle keeps track of its coordinates in the solution region which are associated with the best fitness it has achieved so far. This value is known as 'pbest'. Another 'best' value that is tracked by the particle is the best value, obtained so far by any particle in the group of the particles. This best value is also known as a global best'gbest' and the pattern is forwards to successful solutions. PSO technique using equation (7) is known as the gbest structure. PSO is a population based EA that has many primitive benefits over other optimization techniques. A most attractive quality of the PSO approach is itssimplicity as it involves only two main reference equations. Each particle coordinates represent a possiblesolution assisted with two real vectors.

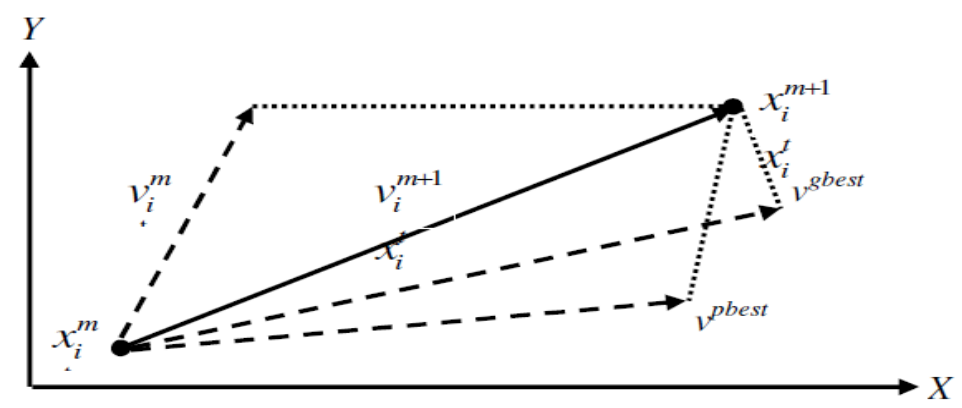

Figure.4.Concept of modification of searching point

Each particle coordinates represent a possible solution assisted with two real vectors. Andvi =[vi1, vi2, vi3...viN] are the two vectors assistedwith each particle ' $\mathrm{i}$ ' in $\mathrm{N}$-dimensional search space.Number of particles or possible solutions of a swarm cango forward through the feasible solution place to explore optimal solutions. Each particle modifies its position based on its own best exploration, and overall experience of best particles (Beielstein et al., 2003). This particle also considers its previous velocity vector according to the following reference equations,

\section{Velocity modifications}

Each particle velocity can be modified by the following equation:

$$
\mathrm{V}_{\mathrm{i}}^{\mathrm{k}+1}=\mathrm{wV}_{\mathrm{i}}^{\mathrm{k}}+\mathrm{c}_{1} \operatorname{rand}(\ldots) \mathrm{x}\left(\operatorname{pbest}_{\mathrm{i}} \mathrm{s}_{\mathrm{i}}^{\mathrm{k}}\right)+\mathrm{c}_{2} \operatorname{rand}_{2}(\ldots) \times\left(\text { gbest-s }_{\mathrm{i}}^{\mathrm{k}}\right)(4)
$$

\section{Position modifications}

Positions of the particles are modified at each interval of the flying time. The position of the particle may bechange or not change, depending on the solution value.

$$
x_{i}^{k+1}=x_{i}^{k}+v_{i}^{k+1}
$$

Where, $\mathrm{v}_{\mathrm{i}}$ is velocity of particle ' $\mathrm{i}$ ' at iteration $m$.

$\mathrm{V}_{\mathrm{i}}^{\mathrm{m}+1}=w^{*} \mathrm{~V}_{\mathrm{i}}^{\mathrm{m}}+c_{1}{ }^{*} r_{1}{ }^{*} \mathrm{x}\left(\right.$ pbest $\left._{\mathrm{i}}-x_{i}{ }^{m}\right)+c_{2}{ }^{*} r_{2}{ }^{*} \mathrm{x}\left(\right.$ gbest $\left._{\mathrm{i}}-x_{i}{ }^{m}\right)$

Typical values for the inertia parameter are in the range $[0.5,1]$. On the other side several different approaches using a construction factor $s$, which increase the algorithm's capability to converge to a better solution and the equation used to modify the particle's velocity 
$\mathrm{V}_{\mathrm{i}}^{\mathrm{m}+1}=s^{*}\left(\mathrm{~V}_{\mathrm{i}}^{\mathrm{m}}+c_{1}{ }^{*} r_{1}^{*}\left(\right.\right.$ pbest $\left._{\mathrm{i}}-x_{i}^{m}\right)+c_{2}{ }^{*} r_{2}^{*} \mathrm{x}\left(\right.$ gbest $\left.\left._{\mathrm{i}}-x_{i}{ }^{m}\right)\right)(7)$

Where,

$\frac{2}{\left|2-\varphi-\sqrt{\varphi^{2}}-4 \varphi\right|}, c_{1}+c_{2}=\varphi \leq 1(8)$

The PSO algorithm with constriction factor can be considered as a special case of the algorithm with inertia weight since the parameters are interacted through the Eqn[8].From investigational studies, the best approach to use with PSO as a rule of thumb is to utilize the constriction factor approach or utilize the inertia weight approach while selecting $\mathrm{w}, \mathrm{c}_{1}$ and $\mathrm{c}_{2}$ according to Eqn [8].

\section{VII.Design Of PSO Based Controller}

Step1.The minimum and maximum gain limits of PI controllers are specified from the conventional PI controller. The initial Particle matrix of(N X 4)is generated by selecting a value with a uniform probability over the search space $\left(\mathrm{G}_{\min }=0, \mathrm{G}_{\max }=1\right)$.

Step2.The initial Particle velocities are set to zero.

Step3. Evaluate the initial population by simulating the Load frequency Control block model with each particle row value as the PI controller gain value and calculate Performance index (ISE/ITAE) for each particle.

Step4. Initialize local minimum $\left(\mathrm{P}_{\text {best }}\right)$ for each particle.

step5. Find the best particle $\left(\mathrm{G}_{\text {best }}\right)$ in initial particle matrix based on the minimum performance index.

Step6. Start the iteration iter=1

Step7. Update the velocity of the particle using the equation shown below,

Velocity $=\mathrm{C} *\left(\mathrm{w}^{*}\right.$ velocity $+\mathrm{c} 1 * \mathrm{r} 1 *\left(\mathrm{P}_{\text {best }}\right.$-Particle $)+\mathrm{c} 2 * \mathrm{r} 2 *\left(\left(\right.\right.$ ones $\left.(\mathrm{N}, 1) * \mathrm{G}_{\text {best }}\right)-$ Particle $\left.)\right)$

Where

Constriction factor $\mathrm{C}=1$

Cognitive parameter $\mathrm{c} 1=1$

Social parameter $\mathrm{c} 2=4-\mathrm{c} 1$

Inertia weight $\mathrm{w}=($ maximum iter- iter $) /$ maximum iter

$\mathrm{r} 1, \mathrm{r} 2$ are the random numbers between 0 and 1

Step8. Create new particle from the updated velocity.

Step9. If any of the new Particles violate the search space limit then choose the particle and generate new values Within the particle search space.

Step10. Evaluate the performance index value for each new particle by simulating the LFC block model.

Step11.Update the best local position $\left(\mathrm{P}_{\text {best }}\right)$ for each particle based on the minimum value comparison between new Particle performance index and old $\mathrm{P}_{\text {best }}$ performance index.

Step12. Update Gbest Global minimum particle and its performance index.

step13.Iter=iter+1

step14.If iter $<=$ maxiter go to step 7, otherwise go to next step.

step15.Print the global best PID controller gain values and its performance index value. 


\section{Simulation Results And Analysis}

The objective of the simulations was to test the PSOcontrol algorithm proposed in this study for AGC of two-area interconnected power systems with reheat non linearity. Simulations were performed using Mat lab Simulink. The step load disturbance of 0.01 p.u. is applied in area-1 for PSO based controller and the frequency oscillations and tie-line power flows are investigated. System dynamic performances, in terms of the deviations of frequencies of each area and tie-line power flows, are shown in Figs. 5 through 11. It can be noticed from these figures that the PSO based controller is very effective in damping the frequency and tie-line power oscillations and reduces the settling time, overshoot and undershoot as compared to other controllers.

TABLE IDynamic response values in area1 during the disturbance.

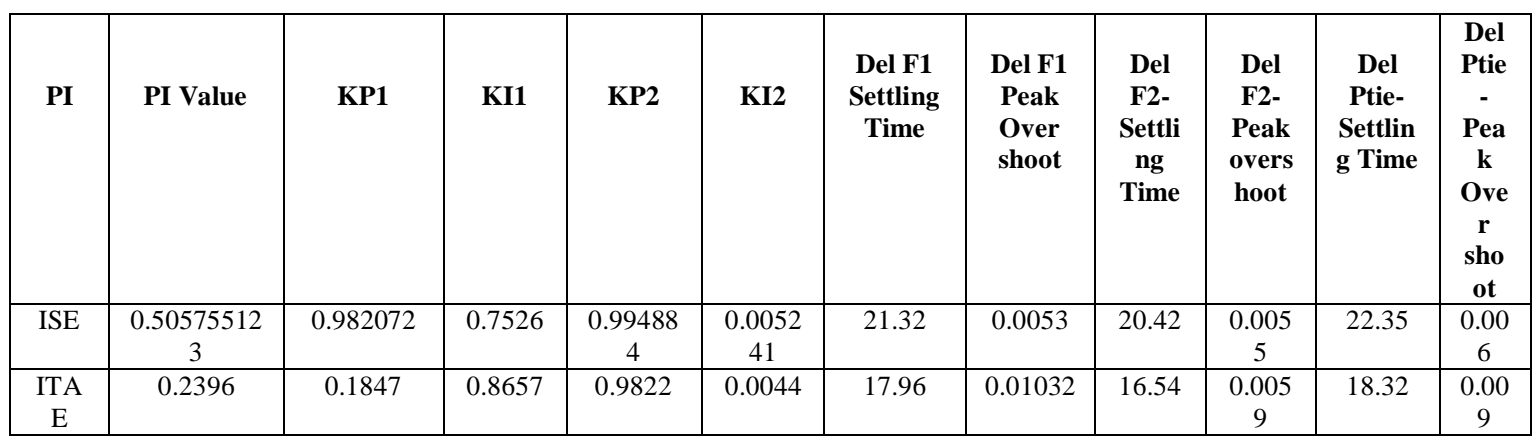

TABLE II Dynamic response values in area2 during the disturbance.

\begin{tabular}{|c|c|c|c|c|c|c|c|c|c|c|c|}
\hline PI & $\begin{array}{l}\text { PI } \\
\text { VALUE }\end{array}$ & KP1 & KI1 & KP2 & KI2 & $\begin{array}{l}\text { Del F1- } \\
\text { Settling } \\
\text { Time }\end{array}$ & $\begin{array}{l}\text { Del } \\
\text { F1- } \\
\text { Peak } \\
\text { Over } \\
\text { shoot }\end{array}$ & $\begin{array}{l}\text { Del F2- } \\
\text { Settling } \\
\text { Time }\end{array}$ & $\begin{array}{l}\text { Del } \\
\text { F2- } \\
\text { Peak } \\
\text { Over } \\
\text { shoot }\end{array}$ & $\begin{array}{l}\text { Del } P_{\text {tie }} \\
\text { Settling } \\
\text { Time }\end{array}$ & $\begin{array}{l}\text { Del } P_{\text {tie- }} \\
\text { Peak } \\
\text { Over } \\
\text { shoot }\end{array}$ \\
\hline ISE & 0.507011 & 0.999387 & 0.060462 & 0.995164 & 0.774302 & 25.2 & 0.006 & 22.39 & 0.0055 & 21.94 & 0.005 \\
\hline ITAE & 0.243611 & 0.966938 & 0.002688 & 0.15909 & 0.801862 & 17.2 & 0.0063 & 19.96 & 0.0093 & 18.12 & 0.00678 \\
\hline
\end{tabular}

Table IIIComparison performance of controllers.

\begin{tabular}{|c|c|c|}
\hline & Settling time & Peak over shoot time \\
\hline With ANN controller & 21.75 & 0.012506 \\
\hline With PSO controller & 21.32 & 0.0053 \\
\hline$\%$ improvement & 1.97 & 0.577 \\
& & \\
\hline
\end{tabular}

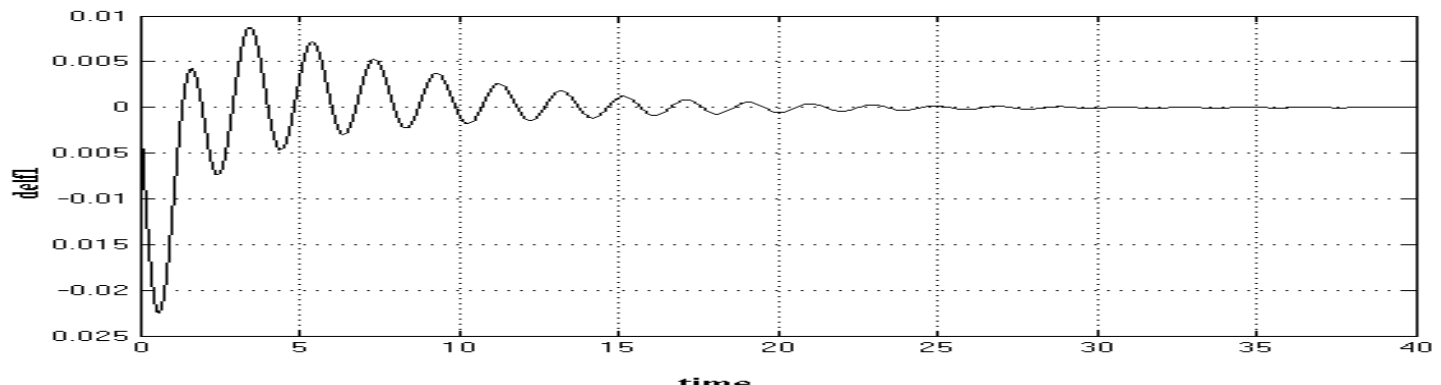

Fig.5. Frequency deviations in area 1 with thermal reheat power system with pso controller. 


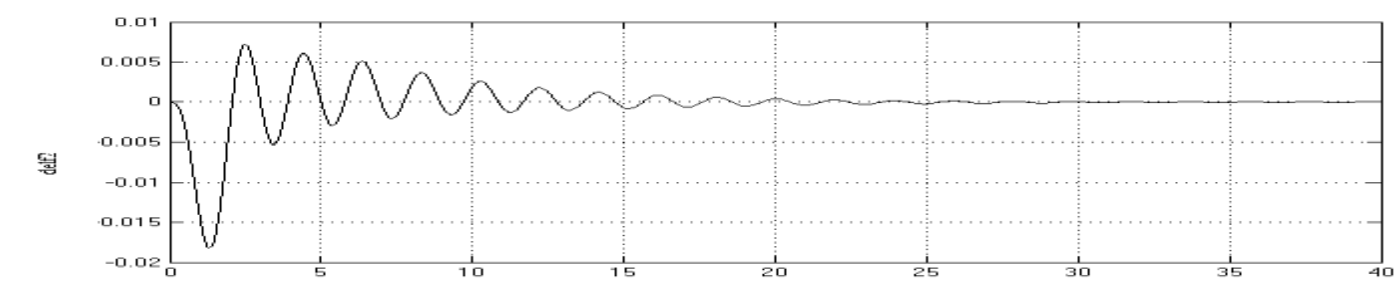

Fig.6.Frequency Deviations in area 2 with thermal reheat power system with integral and pso controller for $1 \%$ step load disturbance.

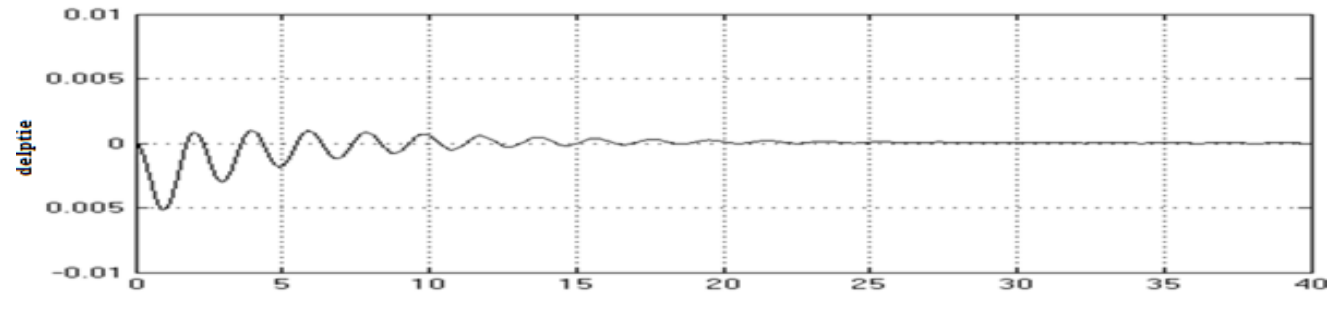

Fig .7. Tie-line power Deviations in a two area interconnected thermal reheat power system with pso controller.

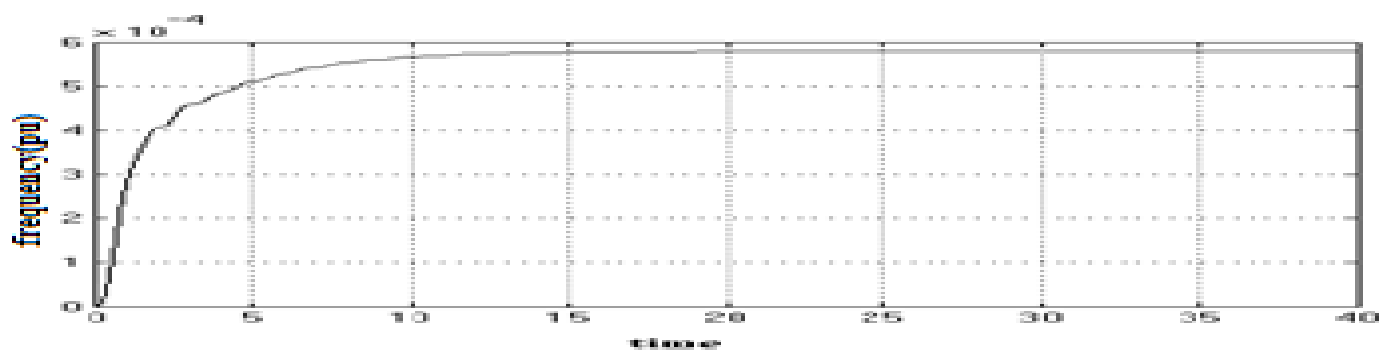

Fig.8.Minimized frequency variation after integral squared error method

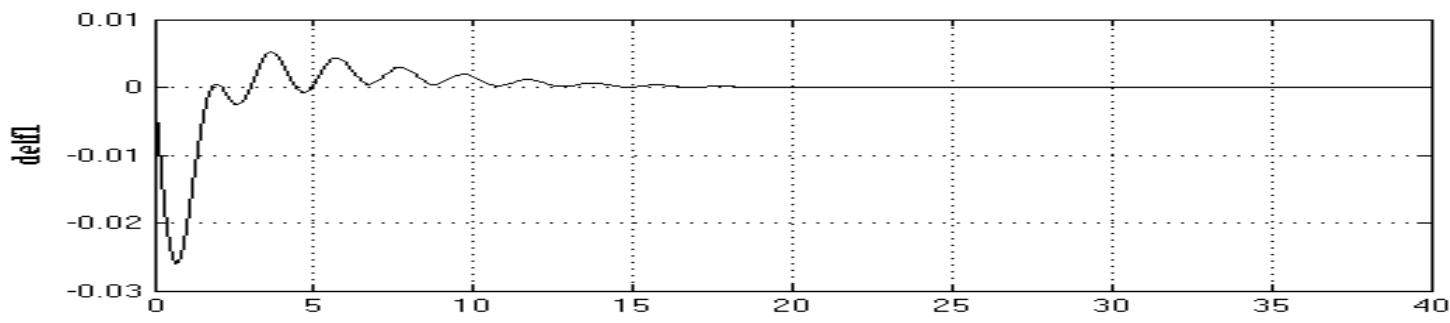

time

Fig.9.Frequency Deviations in area 1 with thermal reheats power system with pso controller for using ITAE method.

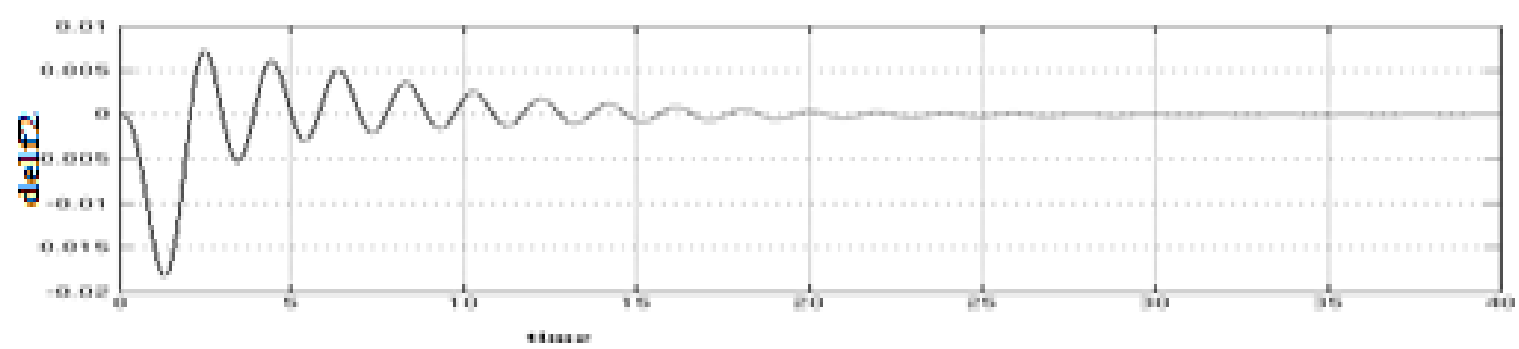

Fig.10 .frequency Deviations in area 2 with thermal reheat power system with integral and pso controller for $1 \%$ step load disturbance using ITAE method.

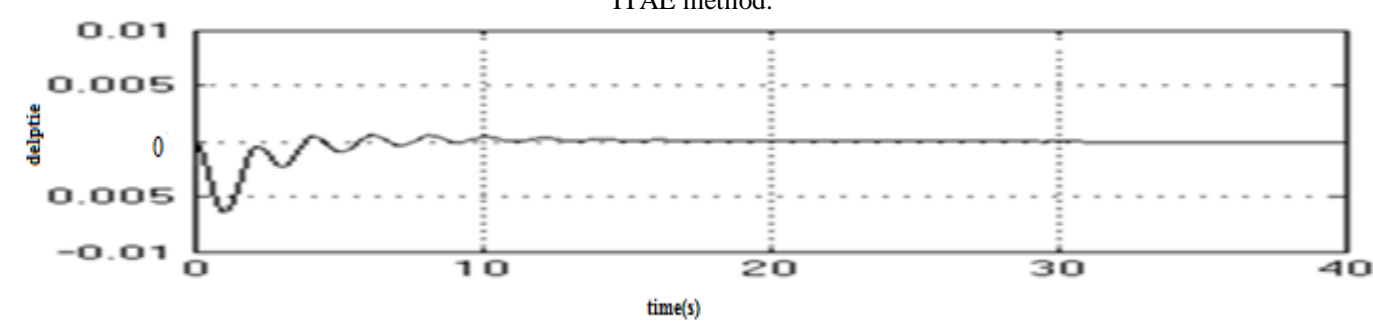

Fig .11.Tie-line power Deviations in a two area interconnected thermal reheat power system with pso controller using ITAE method 


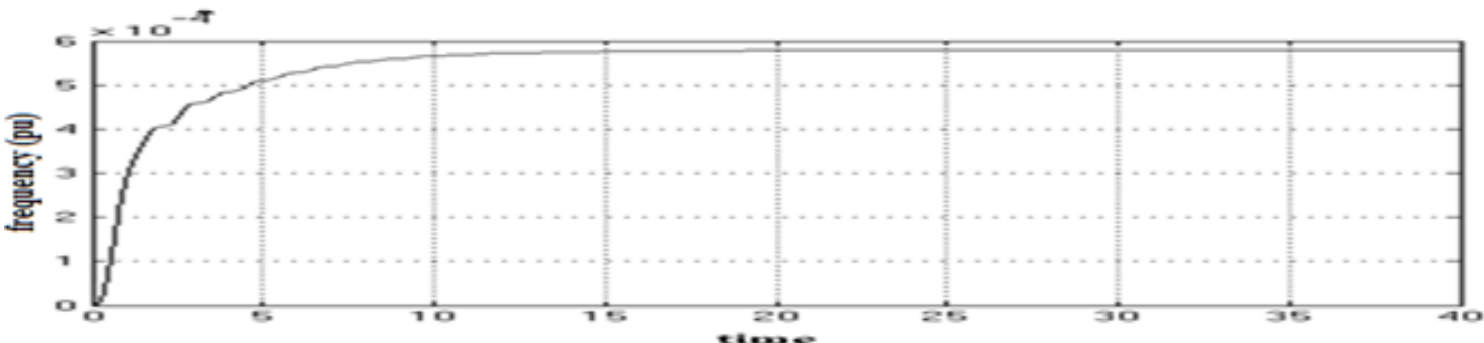

Fig.12. minimized frequency variation after IT AE method.

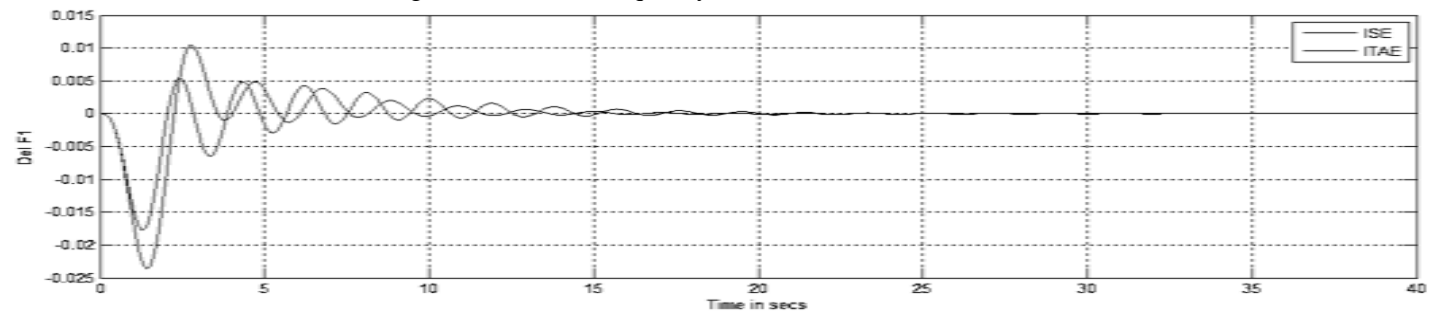

Fig. 13.comparison of area frequency 1 for ISE and ITAE method.

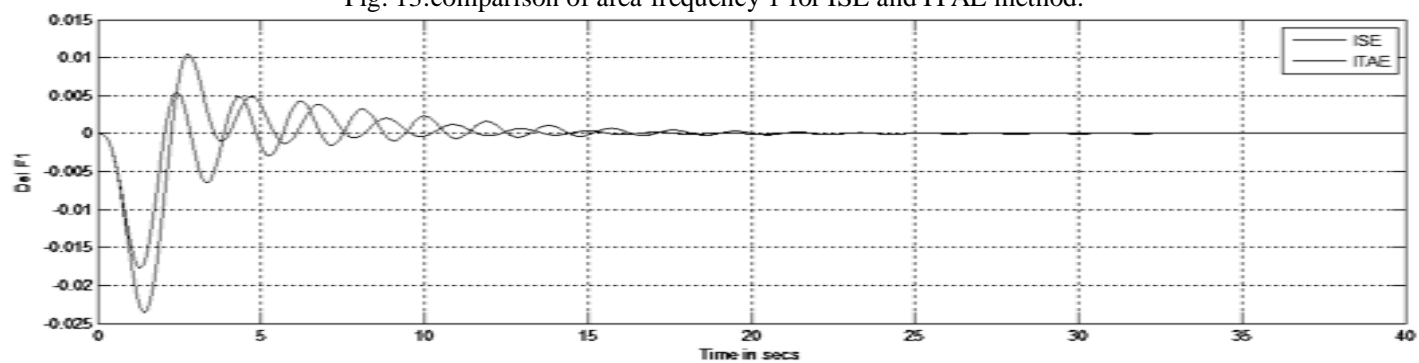

Fig.14.Comparison of area frequency 2 for ISE and ITAE method.

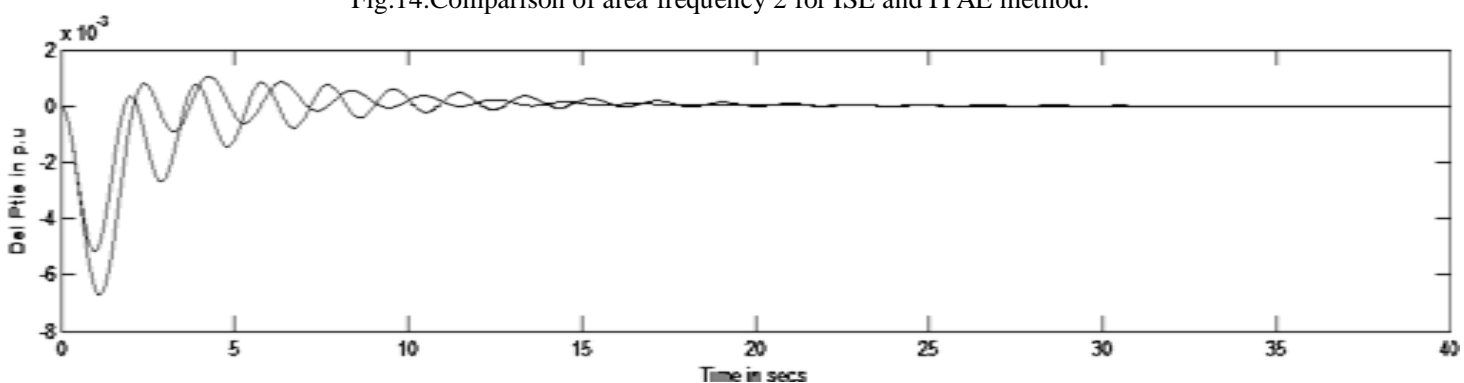

Fig.14.Comparison of area tie line frequency for ISE and ITAE method.

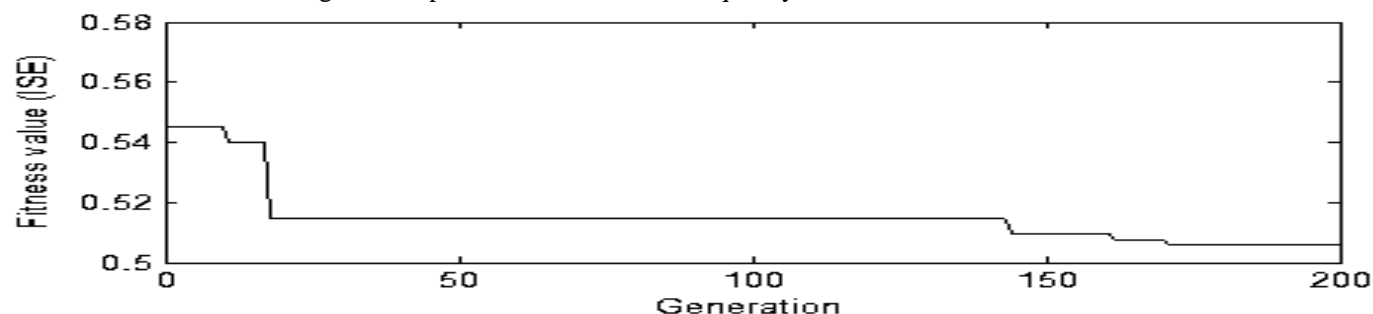

Fig.15.Fitness value graph using ISE method.

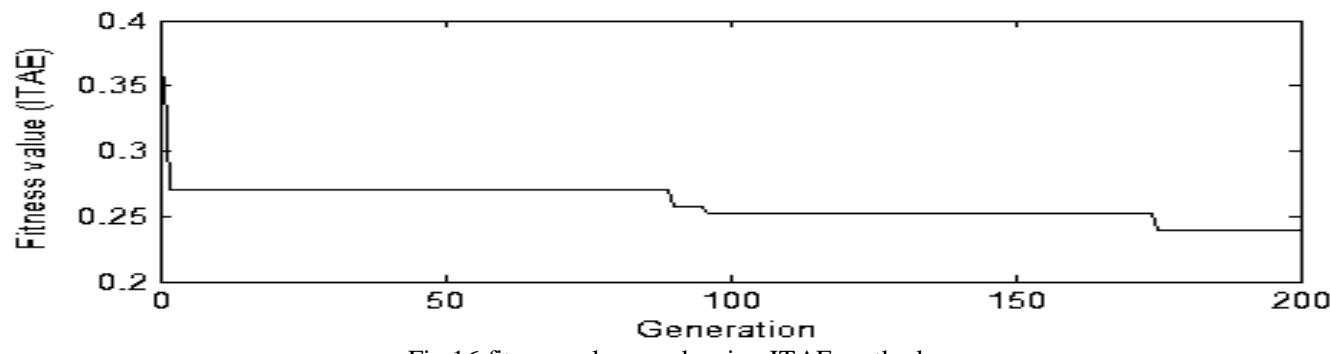

Fig.16.fitness value graph using ITAE method. 


\section{Conclusion}

Particle swarm optimization has been successfully applied to tune the parameters of automatic generation control systems of the integral and the integral-plus-proportional type. A two-area reheat thermal system was assumed to demonstrate the method. The integral square of the error (ISE) and the integral of timemultiplied absolute value of the error (ITAE) were used as objective functions. The superiority of the ITAE in the damping and settling of the transient responses was demonstrated. The effectiveness of the proposed controller in increasing the damping of local and inter area modes of oscillation is demonstrated in a two area interconnected power system. Also the simulation results are compared with a conventional PI controller. The result shows that the proposed PSO controller is having improved dynamic response and at the same time faster than conventional PI controller.

\section{References}

[1] Gayadhar Panda, Sidhartha Panda and, Heider Ali shavenger "Automatic Generation Control of Interconnected Power System with Generation Rate Constraints by Hybrid Neuro Fuzzy Approach international Journal of Electrical and Electronics Engineering 3:9 2009

[2] saikiajanardannandha, Fellow, S. Mishra, Senior Member, and Lalit Chandra "optimization technique in multi area automatic generation controlVol. 26, No. 2,May 2008

[3] Hassan Bahrain, Fatimah Danas far \& Takashi Hisami “ A New Intelligent Agent-Based AGC Design With Real-Time Application", National systems conference, December 17-19 2008

[4] Shamrock shojaein, ajar sultana "A genetic algorithm based a AGC of a restructed power system", journal of Theoretical and Applied Information Technology 2010

[5] "Pārbati Kumar, Sofia A Kami, Nazis basemen "Comparative study of automatic generation control in traditional and deregulated power environment Journal of Electrical engineering Vol. 57, NO. 6, 2006, 305-317, 2009

[6] Parba Kumar, Sofia A Karma, Nazis Basemen "Genetic Algorithm Based scheme for optimization of AGC GAINS of Interconnected power system” IEEE Transactions on circuits and systems, Vol. 55, NO. 9, October 2011

[7] Hussein Sheehy, Heidi Ali Shan far "Real time simulation of AGC for interconnected power system" IEEE Transactions on Power Systems, Vol. 14, No. 4, November, 2010.

[8] J.nanda, fellow ieeem.paridakalam"Automatic generation control of a multi-area power system with conventional integral controllers" dept.of elect.engg.,indian institute of technology Delhi, India Victoria university, Melbourne, Australia.

[9] S.Farook1,*P.SangameswaraRaju2 "Feasible AGC Controllers to Optimize LFC Regulation in Deregulated Power System Using Evolutionary Hybrid Genetic Firefly Algorithm J. Electrical Systems 8-4 (2012): 459-471. S. [10] K. Sinha, R. N. Patel, Member, IEEE, and R. Prasad, Member, SSI Application of GA and PSO Tuned Fuzzy Controller for AGC of Three Area Thermal Hydro Power System International Journal of Computer Theory and Engineering, Vol. 2, No. 2 April, 2010.

[11] Pardeep Nain Assistant Professor MUIT, Hansi Haryana, India K. P. Singh Parmar Assistant Director (Technical) CAMPS, NPTI, Faridabad Haryana, India, 121003 A. K. Singh Associate Professor DCRUST, Murthal Haryana, India" Automatic Generation Control of an Interconnected Power System Before and After Deregulation"International Journal of Computer Applications (0975 - 8887) Volume 61- No.15, January 2013.

[12] Youssef L. Abdel-Magid M. A. Abido"AGC tuning of interconnected reheat thermal systems with particle swarm optimization" Electrical Engineering Department King Fahd University of Petroleum \& Minerals, Dhahran 31261, Saudi Arabia.

[13] Ibraheem, NaimulHasan and Omveer SinghGASA tuned optimal fuzzy regulator for AGC of an interconnected power system "International Journal of Computer Applications (0975 - 8887) Volume 20- No.8, April 2011.

[14] Ibraheem and Omveer Singh "Current Philosophies of Intelligent Techniques based AGC for Interconnected Power Systems" Canadian Journal on Electrical and Electronics Engineering Vol. 3, No. 7, September 2012.

Jeevitha venkatachalam - She hasreceived the B.E degree in Electrical and Electronics Engineering from sengunthar engineering college, tiruchengode, Tamilnadu, India under Anna UniversityCoimbatore in 2011 and currently perusing M.E. in Power Systems Engineering from Paavai Engineering College, Nammakal, Tamil Nadu, India under Anna University, Chennai (2011-2013).

Rajalaxmi.s- She hasreceived the B.E degree in Electrical and Electronics Engineering from Mahindra engineering college, Tiruchengode, Tamilnadu, India under AnnaUniversity Chennai, She has received M.E degree in Applied Electronics from Paavai engineering college Nammakal and currently working as Associate Professor in EEE Department in Paavai Engineering College, Nammakal, Tamil Nadu, India under Anna university, Chennai. 